\title{
Adsorption of Mussel Protein on Polymer Antifouling Membranes: A Molecular Dynamics Study
}

\author{
Fengfeng Gao
}

\begin{abstract}
Department of Chemical Engineering, Zibo Vocational Institute, Zibo 255300, China; 11364@zbvc.edu.cn; Tel.: +86-533-2348221
\end{abstract}

\begin{abstract}
Biofouling is one of the most difficult problems in the field of marine engineering. In this work, molecular dynamics simulation was used to study the adsorption process of mussel protein on the surface of two antifouling films—-hydrophilic film and hydrophobic film—trying to reveal the mechanism of protein adsorption and the antifouling mechanism of materials at the molecular level. The simulated conclusion is helpful to design and find new antifouling coatings for the experiments in the future.
\end{abstract}

Keywords: antifouling membrane; protein adsorption; mussel protein; hydrophilic film; hydrophobic film

Citation: Gao, F. Adsorption of

Mussel Protein on Polymer

Antifouling Membranes: A Molecular Dynamics Study. Molecules 2021, 26, 5660. https://doi.org/10.3390/ molecules 26185660

Academic Editors: Shiling Yuan and Heng Zhang

Received: 17 August 2021

Accepted: 14 September 2021

Published: 17 September 2021

Publisher's Note: MDPI stays neutral with regard to jurisdictional claims in published maps and institutional affiliations.

Copyright: (C) 2021 by the author. Licensee MDPI, Basel, Switzerland. This article is an open access article distributed under the terms and conditions of the Creative Commons Attribution (CC BY) license (https:// creativecommons.org/licenses/by/ $4.0 /)$.

\section{Introduction}

Marine fouling is one common problem for ships and marine facilities. The adhesion of marine organisms leads to the increase of hull surface roughness, which can increase the resistance of navigation, and the organic acids released by these organisms also accelerates the corrosion of ships and marine facilities. Worldwide, the cost of fuel consumption, hull cleaning, painting, and maintenance caused by marine fouling is about several billions of dollars per year.

In order to reduce the loss caused by marine fouling, the common method is to apply antifouling coating on the surface of ship. The traditional antifouling coating is mixed with organic copper, organic tin, etc., and these coating are mainly to kill the marine organisms attached to the hull surface by releasing heavy metal ions. However, these heavy metal ions accumulate in the food chain and eventually endanger human beings [1]. At present, designing and developing new environmentally friendly marine antifouling coatings has become a hot new trend in the field of biological antifouling.

There are many kinds of adhesion marine organisms in the ocean, including algae, shellfish, sponge, etc. Among them, shellfish (such as barnacles, mussels, etc.) are more difficult to treat. Normally, the attachment mechanism of them depends on their own released proteins temporarily or permanently adhering to the solid surface (such as the hull). At present, the adhesion materials being widely studied are barnacle glue and mussel protein in most of research experiments. In these experiments, the adsorption of proteins on the surface of materials is related to their own properties (such as surface charge, hydrophobicity, conformation, etc. [2,3]) and the materials surface's properties (such as surface roughness, chemical composition, etc.).

Till now, there has not been a unanimous view about antifouling mechanism. However, it is generally known that the hydration layer on the surface of materials has a great relationship with its antifouling effect [4-6]. A large number of experimental studies show that the antifouling effect of a hydrophilic surface is better than that of a hydrophobic surface $[7,8]$. This contributed that one closely bonded hydration layer can be formed on the surface of hydrophilic materials, and the adsorption process of proteins must destroy the hydration layer firstly. Therefore, the binding ability between water molecules and membrane materials can reflect the difficulty of binding between proteins and solid surfaces [9-12]. 
It is very important to understand the interaction mechanism between protein and solid surface for both theoretical and applied research. In order to design and find new antifouling materials, it is necessary to study the adsorption mechanism between biological proteins and antifouling materials. However, it is very difficult to reveal the internal mechanism of adsorption at the molecular level for any experimental technique. In this paper, we used molecular dynamics method to study the adsorption behavior of mussel protein on different materials surface, and we will try to explain the adsorption mechanism of mussel protein and the antifouling mechanism of the material surface on the microscopic level.

\section{Simulation Method}

Polymer antifouling membrane is constructed by Amorphous cell module in Materials Studio Software (version 4.4). Firstly, the dimethylsiloxane (PDMS) layer was constructed. Its density is $0.965 \mathrm{~g} / \mathrm{cm}^{3}$ and the thickness of the membrane is about $2 \mathrm{~nm}$. Then, alkyl chains of $-\left(\mathrm{CH}_{2}\right)_{10} \mathrm{CH}_{3}$ and $\left.-\left(\mathrm{CH}_{2}\right)_{10} \mathrm{COOH}\right)$ are grafted on the surface of PDMS, respectively, and the grafting number density is about 0.66 per square nanometer. Finally, $\mathrm{CH}_{3}$-SAM and $\mathrm{COOH}-S A M$ polymer antifouling membrane are obtained. Both represent the hydrophobic and hydrophilic antifouling membrane, respectively [13-16].

In the simulation, mussel protein (PDB ID: 5DUY) is used as the model protein, which contains 150 amino acid molecules. It is similar to the spherical structure and contains a typical secondary structure. At first, mussel protein is placed $0.5 \mathrm{~nm}$ above the surface of the two antifouling membranes (shown in Figure 1), and six chloride ions are randomly placed as counterions to balance the positive charge of the protein. The same thickness of water layer is added above the two polymer membranes. In order to eliminate the possible high energy caused by conformational overlap, the water molecules in the range of $0.2 \mathrm{~nm}$ around the protein and polymer membranes are deleted $[17,18]$.

(a)

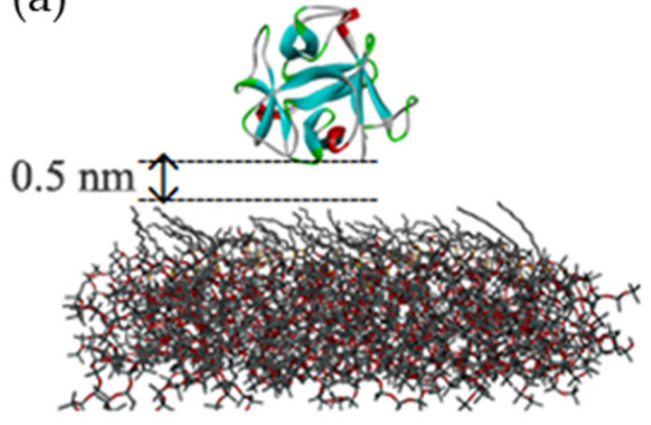

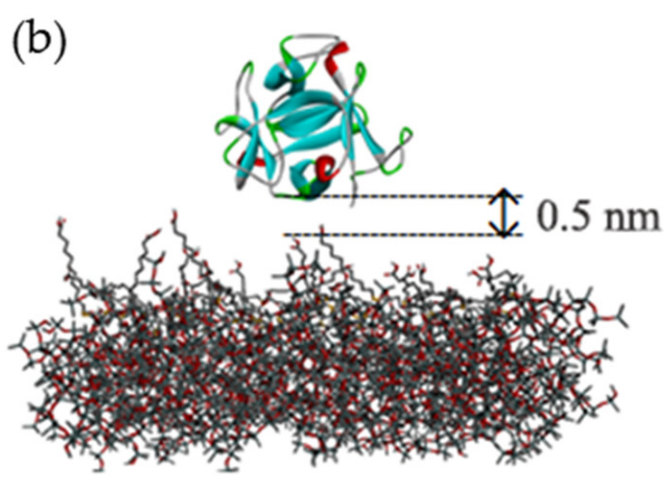

Figure 1. Initial configuration of system: (a) protein on the surface of CH3-SAM membrane; (b) protein on the surface of COOH-SAM membrane.

In the simulation, the united-atomic force field GROMOS 45a3 is selected [19] and the software package GROMACS (version 4.5.5), is carried out to run the molecular dynamic calculation [20,21]. First of all, for the initial configuration, the steepest descent method was performed several hundred steps to eliminate conformational overlap; then, the NVT ensemble was run for at least $25 \mathrm{~ns}$ to obtain the equilibrium of system; then, another $75 \mathrm{~ns}$ MD simulation was run to find out the statistical information about mussel protein and the antifouling membrane. During the simulation, in order to reduce the simulation time, the PDMS layers are fixed, and the periodic boundary conditions in XYZ directions are used. For the solvent water, the single point charge (SPC) model is selected [22]. In the simulation, the PME method was used to handle the long-range electrostatic interaction [23], and the radius of non-bond interaction was $1.2 \mathrm{~nm}$. The Berendsen method was used to control the temperature [24], and the LINCS method was selected to constraint the bond of molecule [25]. The simulated step was $2 \mathrm{fs,} \mathrm{and} \mathrm{the} \mathrm{trajectory} \mathrm{of} \mathrm{system} \mathrm{was} \mathrm{stored} \mathrm{each}$ 100 ps. In the production of simulation, GROMACS analysis program is used to analyze 
the simulation results, and VMD software (version 1.9.3), is used to visualize the molecular dynamics trajectory.

\section{Results and Discussions}

\subsection{Adsorption Process}

In Figure 2, the centroid distance between mussel protein and polymer membrane was calculated, and the variation of minimum distance with time evolution was shown. It is obvious that the distance between mussel protein and polymer membrane for the two systems decreased rapidly and reached equilibrium at a short simulated time, indicating that mussel protein can reach a stable adsorption state for the present simulated model at a short simulated time. We noted that the distance between protein and membrane fluctuated greatly, which indicated that protein constantly adjusted its own configuration during the process of adsorption until an optimal site for adsorption was finally obtained [13-16].

(a)

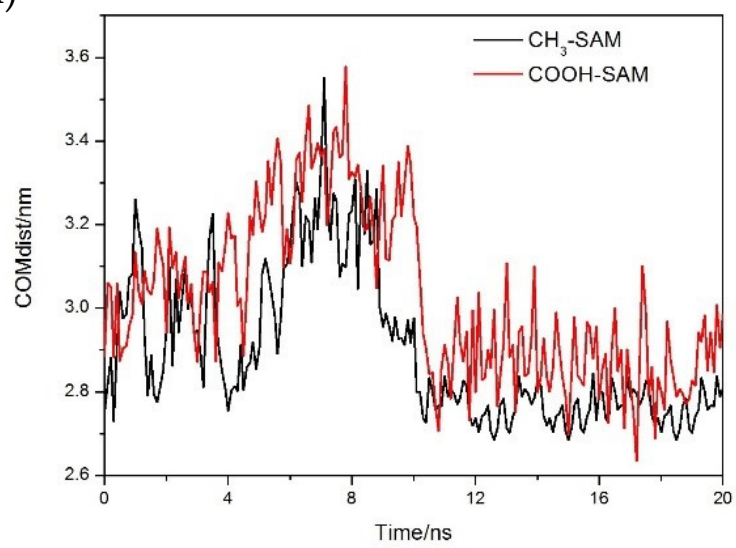

(b)

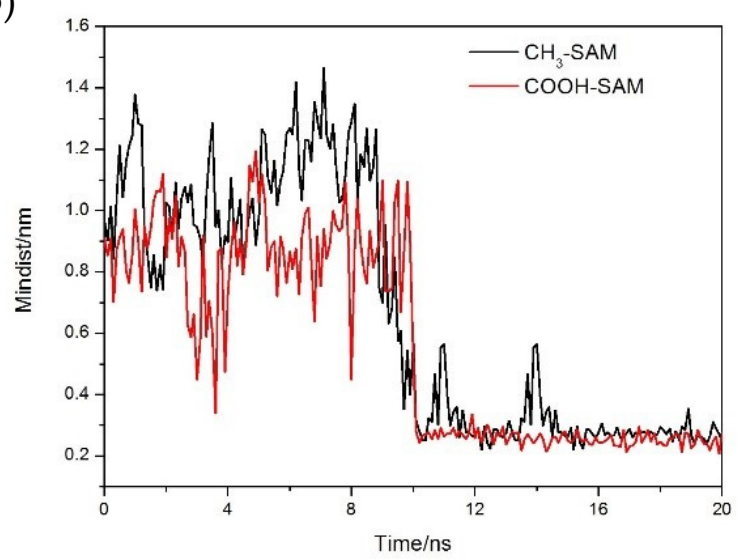

Figure 2. (a) The variation of the distance between mussel protein core and antifouling membrane with time; (b) the variation of the minimum distance between mussel protein and antifouling membrane with time.

After the adsorption equilibrium of protein was obtained, the residue types of amino acid of protein on the $\mathrm{CH}_{3}$-SAM and COOH-SAM polymer antifouling membrane can be divided, and the results are shown in Table 1. By comparing the residue types of mussel proteins on different self-assembled membrane surfaces, we noted that the nonpolar residues are major on the surface of $\mathrm{CH}_{3}$-SAM membrane, while the polar residues are major on the surface of COOH-SAM membrane (Figure 3). We speculate that the surface of protein contains hydrophilic polar residues, and the hydrophobic nonpolar residues are mostly in its interior of spherical protein. When the protein interacts with the $\mathrm{CH}_{3}-\mathrm{SAM}$ membrane, the hydrophobic residues can be turned over from the interior and form the better combination between the hydrophobic $\mathrm{CH}_{3}-\mathrm{SAM}$ surface and hydrophobic residues of protein. In order to prove the speculation, we calculated the interaction energy between mussel protein and two self-assembly membranes, respectively. As shown in Figure 4, it is obvious that the non-bond interaction energy between $\mathrm{CH}_{3}$-SAM membrane and mussel protein is greater than that between $\mathrm{COOH}-\mathrm{SAM}$ membrane and the protein. This shows that the hydrophobic surface has a stronger effect on mussel protein molecules, and the adsorption of mussel protein on its surface is more stable and difficult to be separated. At the same time, we noted that the proportion of van der Waals (VDW) interaction is much larger than that of Coulomb interaction during the simulation process. For $\mathrm{CH}_{3}-\mathrm{SAM}$ surface, the VDW energy is about $320 \mathrm{~kJ} / \mathrm{mol}$, which is approximately $94 \%$ contribution to the total energy. While the VDW energy for COOH-SAM surface is about $180 \mathrm{~kJ} / \mathrm{mol}$, contributing to $90 \%$ to the total energy. These indicate that the driving force of protein adsorption is mainly van der Waals interaction between protein and membrane [26]. 
Table 1. Statistics of residue types of mussel protein on polymer membrane surface.

\begin{tabular}{ccc}
\hline System & Polar (\%) & Nonpolar (\%) \\
\hline $\mathrm{CH}_{3}$-SAM & $21.05 \pm 0.05$ & $78.95 \pm 0.05$ \\
$\mathrm{COOH}-S A M$ & $71.42 \pm 0.05$ & $28.75 \pm 0.05$ \\
\hline
\end{tabular}
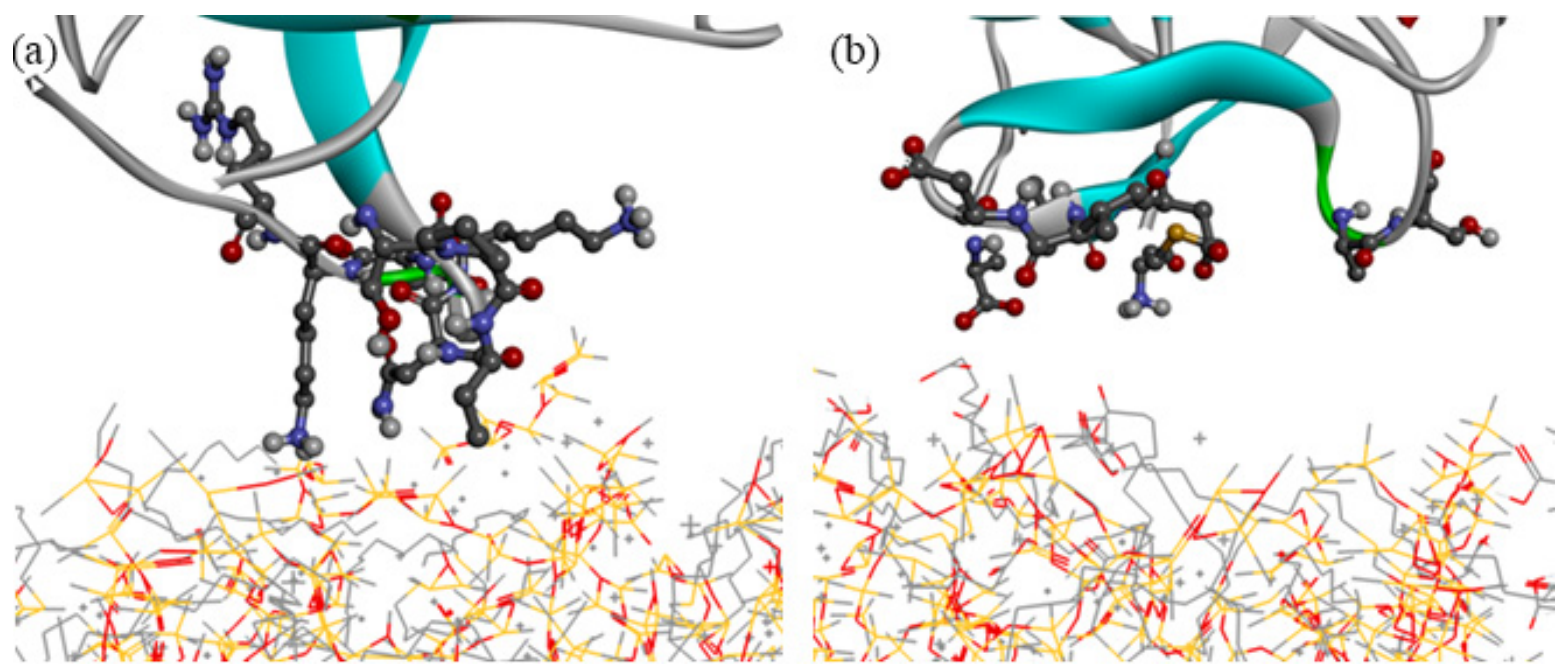

Figure 3. Partial enlarged drawing after stable adsorption. (a) $\mathrm{CH}_{3}-\mathrm{SAM}$ surface of self-assembled membrane. (b) $\mathrm{COOH}-$ SAM membrane surface.

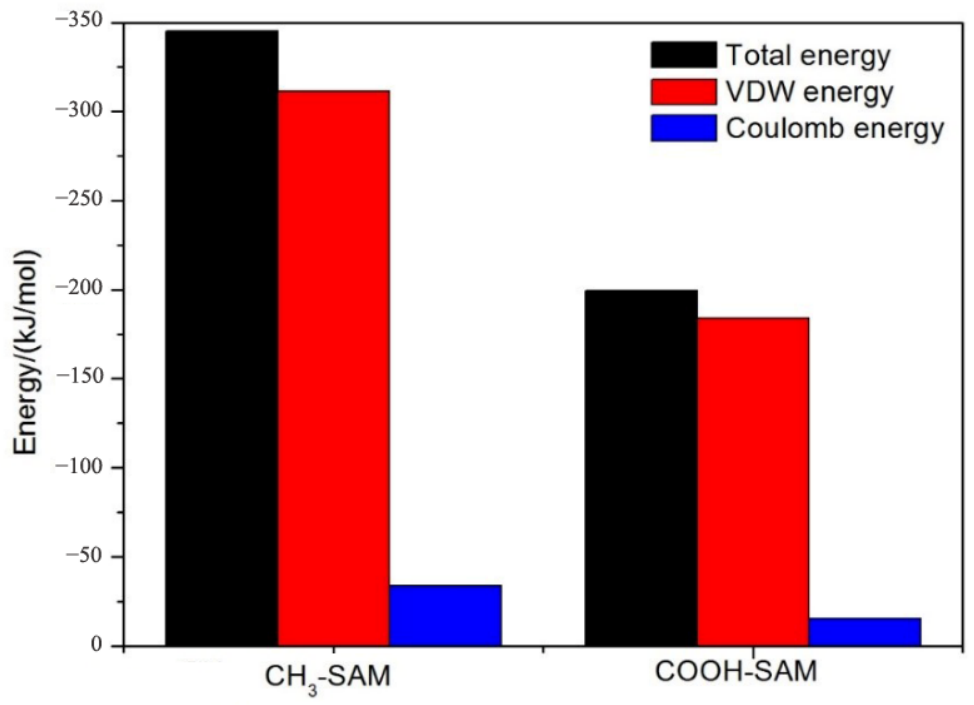

Figure 4. Energy diagram of non-bond interaction between mussel protein and substrate.

\subsection{Properties of Hydration Layer on Membrane Surface}

The antifouling ability of materials is closely related to the surface hydration layer [4,27]. The hydration layer can act as a physical barrier when the protein is close to the surface of material, and we evaluate the antifouling ability of the two-polymer membrane by analyzing the structure and stability of the hydration layer.

Firstly, the water molecules in the range of $0.4 \mathrm{~nm}$ on the surface of membrane were defined as the hydration layer. The mean square displacements (MSD) of water molecules in hydration layer with time evolution for the two investigated systems are shown in 
Figure 5. By fitting the two curves and calculating their slopes, the diffusion coefficient (D) of water molecules in the hydration layer can be calculated by Equation (1):

$$
\mathrm{D}=\frac{1}{2 d N} \lim _{t \rightarrow \infty} \frac{d}{d t} \sum_{i=1}^{N}\left\langle\left[r_{i}(t)-\overrightarrow{r_{i}(0)}\right]^{2}\right\rangle
$$

where $N$ represents the number of target molecules in the system, $\overrightarrow{r_{i}(0)}$ and $\overrightarrow{r_{i}(t)}$ represent the coordinates of the ith particle at 0 and $t$, respectively.

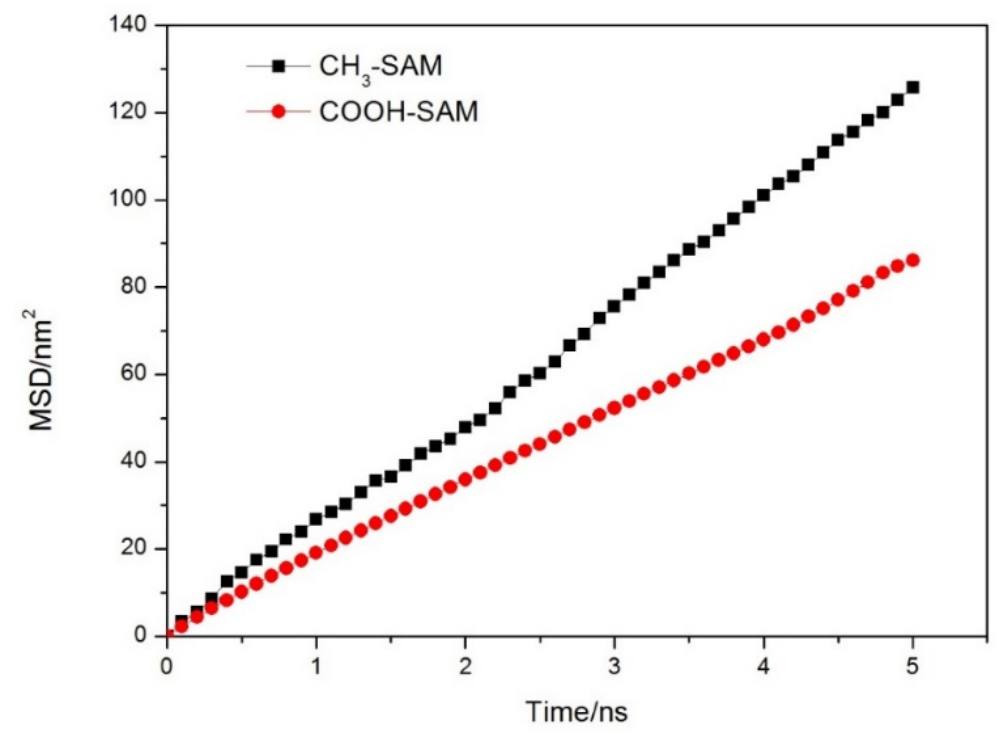

Figure 5. Relation diagram of the variation of average azimuthal shift with time of self-assembled membrane surface hydration layer molecules.

Table 2 lists the Ds of water molecules in the hydration layer and bulk phase. It was found that the $\mathrm{D}$ of water molecules in the hydration layer decreased compared with that in the bulk solution for the two systems. It indicates that the interaction between the surface of materials and water molecules restricted the diffusion of water molecules on the membrane surfaces, especially for the COOH-SAM system. It also shows that the binding ability of COOH-SAM self-assembly membrane to water molecules is relatively stronger. Meanwhile, we also noted that the D of water molecules in the vertical direction is much lower than that in the horizontal direction, indicating that the solvent layer molecules are difficult to separate from the surface of the self-assembled membrane.

Table 2. Some property parameters of solvent layer molecules on the substrate surface.

\begin{tabular}{ccccccc}
\hline \multirow{2}{*}{ System } & \multicolumn{2}{c}{ Diffusion Coefficients $(\mathbf{D s}) \times \mathbf{1 0}^{-\mathbf{5}}\left(\mathbf{c m}^{\mathbf{2}} \mathbf{s}^{-\mathbf{1}}\right)$} & HBs Life $(\mathbf{p s})$ & HBs Num $\left(\mathbf{n m} \mathbf{2}^{\mathbf{2}}\right)$ & $\boldsymbol{\tau}_{\boldsymbol{\mu}}(\mathbf{p s})$ \\
& $\mathbf{D}$ & $\mathbf{D}_{\perp}$ & $\mathbf{D}_{/ /}$ & & \\
\hline $\mathrm{CH}_{3}$-SAM & $3.21 \pm 0.20$ & $0.24 \pm 0.43$ & $3.99 \pm 0.01$ & 74.34 & 0.13 & 46.78 \\
COOH-SAM & $2.56 \pm 0.09$ & $0.19 \pm 0.43$ & $3.73 \pm 0.13$ & 129.88 & 0.25 & 68.82 \\
Bulk water & $3.66 \pm 0.04$ & $3.58 \pm 0.19$ & $3.69 \pm 0.04$ & - & - & 23.93 \\
\hline
\end{tabular}

Relaxation time can describe the limiting ability of antifouling membrane to the molecules of hydration layer. The longer the relaxation time is, the stronger the binding ability of antifouling membrane to water molecules is and representing the better antifouling effect. Its value can be obtained by fitting autocorrelation function [28-30]:

$$
C_{r}(t)=\frac{1}{N_{w}} \sum_{j=1}^{N_{w v}} \frac{\left\langle P_{R j}(0) P_{R j}(t)\right\rangle}{\left\langle P_{R j}(0)\right\rangle^{2}}
$$


where $P_{R j}$ represents a binary operator, if the target molecule $j$ remains in the initial range at time $t$, then $P_{R j(t)}=1$, if not, then $P_{R j(t)}=0 . N_{w}$ is the total number of target molecules in the initial range defined by us, $<>$ represents ensemble average.

Figure 6 shows the relationship of $C(t)$ and the time $t$. It can be seen that the autocorrelation functions of water molecules on the two membrane surfaces show the same trend of decay, and the decay of water molecules on $\mathrm{CH}_{3}$-SAM membrane surface is relatively fast. Fitting the curve using the equation $C_{r}(t)=A_{r} \exp \left(-t / \tau_{\mu}\right)$, the relaxation time $\tau_{\mu}$ can be calculated. Table 2 lists the $\tau_{\mu}$ of hydrated layer molecules and bulk water for the different self-assembled membranes. Due to the existence of polymer membrane, the relaxation time of the surface hydration layer molecules is longer than that of the bulk phase water. It explains that both polymer membranes have limiting effects on the surface hydration layer molecules. The COOH-SAM membrane has greater limiting effect on the hydration layer molecules. Meanwhile, the number and life of hydrogen bonds (HBs) formed between water molecules and self-assembled membrane are also listed in Table 2. The data showed that the number of HBs formed between water molecules and $\mathrm{COOH}-\mathrm{SAM}$ polymer is relatively stronger, and the life of HBs is relatively long. These also explained the reason why water molecules and COOH-SAM polymer can form the strong hydrogen bonding structure.



Figure 6. Autocorrelation function of molecules in hydration layer on polymer membrane surface.

\subsection{Adsorption Mechanism}

In the aqueous environment, a close hydration layer can be formed between mussel protein and antifouling membrane. When the protein molecules in the aqueous approach to the membrane surface, they must destroy the hydration layer first, that is, the adsorption of protein molecules on the antifouling membrane surface is essentially the competitive adsorption behavior between protein molecules and water molecules on the interface. As shown in Figure 7, during the adsorption process, the mussel protein first exposes the hydrophobic residues to the surface through its own structure changes. In this process, the exposure of hydrophobic residues damaged the hydration layer on the surface of the protein. When the protein touches the hydration layer on the membrane surface, in order to complete the adsorption, the energy barrier brought by the hydration layer of the antifouling membrane must be overcome. Due to the different hydrophilicity of antifouling membrane surface, the structure and properties of the surface hydration layer are different. For the hydrophilic carboxyl self-assembled membrane, because the surface contains hydrophilic functional groups, the interaction with water molecules is stronger, and the formed hydration layer is also tighter, so the energy barrier that they should overcome in the process of mussel protein adsorption is larger, which is not conducive to the combination of protein molecules and membrane. However, for the hydrophobic 
methyl self-assembled membrane, the interaction between the surface and water molecules is weaker, and the formed hydration layer is relatively loose. The mussel protein can be adsorbed on the surface of the antifouling membrane by overcoming the smaller energy barrier, and they form a more stable combination through the hydrophobic interaction.

(a) hydrophilic membrane

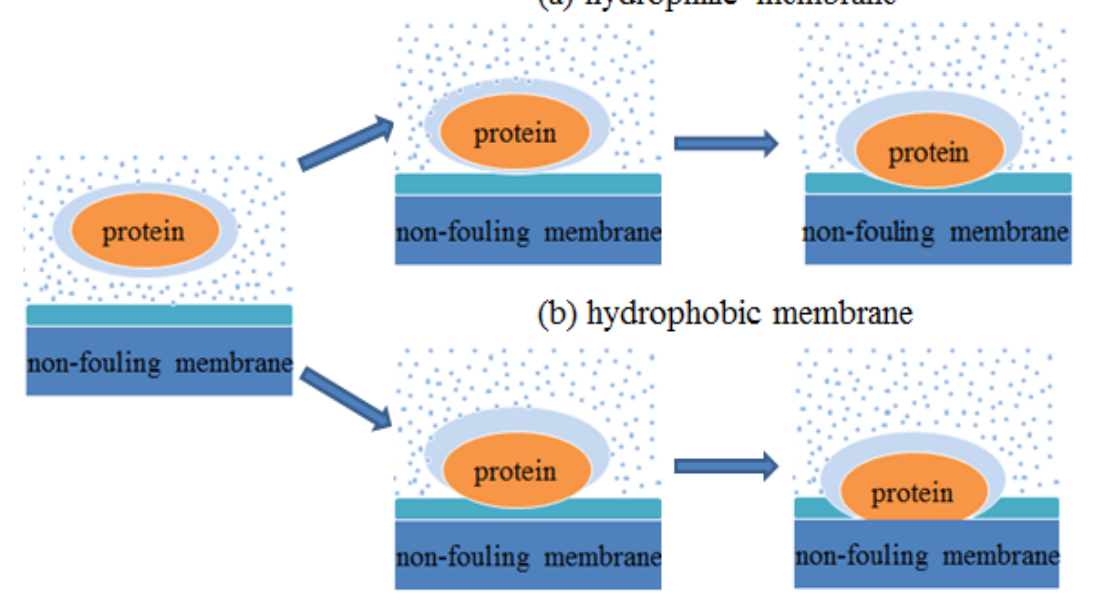

Figure 7. Antifouling mechanism. (a) Adsorption process of protein on hydrophilic membrane surface. (b) Adsorption process of protein on hydrophobic membrane surface.

\section{Conclusions}

The adsorption behavior of mussel protein on the surfaces of two antifouling materials was studied by molecular dynamics simulation. By analyzing the adsorption process, including the distance between the protein centroid and the membrane, the type of residues near the adsorption site, the interaction energy between the protein and the antifouling membrane, the diffusion properties of the hydration layer molecules on the membrane surface and the life of HBs, the following simulated conclusions are listed:

(1) In the process of protein adsorption on the surface of different materials, influenced by the chemical composition and structure of the material surface, it will deform through the rotation of its own skeleton, so as to separate the hydration layer on the surface from the protein and form a stable binding with the material surface at the optimal site.

(2) The interaction between mussel protein and antifouling membrane is mainly van der Waals interaction, and the binding between mussel protein and methyl self-assembled membrane is relatively stable.

(3) When mussel protein is adsorbed on the surface of carboxyl self-assembled membrane, it needs to overcome the energy barrier brought by the dense hydrated layer polarized on the surface of the membrane. Compared with the methyl self-assembled membrane, it has better antifouling performance.

In conclusion, this paper uses molecular dynamics method to compare and study the adsorption process of mussel protein on the surface of COOH-SAM membrane and $\mathrm{CH}_{3}$-SAM membrane and reveals the factors that hydrophilic self-assembled antifouling membrane has better antifouling characteristics from the molecular level, which is of great significance for optimizing and designing new antifouling coatings.

Funding: This research received no external funding.

Institutional Review Board Statement: Not applicable.

Informed Consent Statement: Not applicable.

Data Availability Statement: The data presented in this study is available upon reasonable request.

Conflicts of Interest: The author declares no conflict of interest. 


\section{References}

1. Clare, A.S.; Evans, L.V. Marine Biofouling: Introduction. Biofouling 2000, 16, 81-82. [CrossRef]

2. Puleo, D.A.; Rena, B. Biological Interactions on Materials Surfaces: Understanding and Controlling Protein, Cell, and Tissue Response; Springer: New York, NY, USA, 2009; pp. 1-17.

3. Dee, K.C.; Puleo, D.A.; Bizios, R. An Introduction to Tissue-Biomaterial Interactions; John Wiley \& Sons: Hoboken, NJ, USA, 2002.

4. Zheng, J.; Li, L.; Tsao, H.-K.; Sheng, Y.-J.; Chen, S.F.; Jiang, S.Y. Strong repulsive forces between protein and oligo (ethylene glycol) self-assembled monolayers: A molecular simulation study. Biophys. J. 2005, 89, 158-166. [CrossRef] [PubMed]

5. Sowmi, U.; Michael, P. Analysis of Cooperativity and Group Additivity in the Hydration of 1,2-Dimethoxyethane. J. Phys. Chem. B 2021, 125, 1660-1666.

6. Vanderah, D.J.; La, H.; Naff, J.; Silin, V.; Rubinson, K.A. Control of protein adsorption: Molecular level structural and spatial variables. J. Am. Chem. Soc. 2004, 126, 13639-13641. [CrossRef]

7. Liu, Y.L.; Zhang, Y.X.; Ren, B.P.; Sun, Y.; He, Y.; Cheng, F.; Xu, J.X.; Zheng, J. Molecular dynamics simulation of the effect of carbon space lengths on the antifouling properties of hydroxyalkyl acrylamides. Langmuir 2019, 35, 3576-3584. [CrossRef] [PubMed]

8. Cedervall, T.; Lynch, I.; Foy, M.; Berggard, T.; Donnelly, S.C.; Cagney, G.; Linse, S.; Dawson, K.A. Detailed identification of plasma proteins adsorbed on copolymer nanoparticles. Angew. Chem. Int. Ed. 2007, 46, 5754-5756. [CrossRef]

9. Aggarwal, P.; Hall, J.B.; McLeland, C.B.; Dobrovolskaia, M.A.; McNeil, S.E. Nanoparticle interaction with plasma proteins as it relates to particle biodistribution, biocompatibility and therapeutic efficacy. Adv. Drug Deliv. Rev. 2009, 61, 428-437. [CrossRef]

10. Choi, W.; Jin, J.; Park, S.; Kim, J.-Y.; Lee, M.-J.; Sun, H.; Kwon, J.-S.; Lee, H.; Choi, S.-H.; Hong, J. Quantitative interpretation of hydration dynamics enabled the fabrication of a zwitterionic antifouling surface. ACS Appl. Mater. Interfaces 2020, 12, 7951-7965. [CrossRef]

11. Zheng, H.-R.; Wang, X.-W.; Lin, X.-H.; Geng, Q.; Chen, X.; Dai, W.-X.; Wang, X.-X. Promoted Effect of Polyethylene Glycol on the Photo-Induced Hydrophilicity of $\mathrm{TiO}_{2}$ Films. Chim. Sin.-Acta Phys. 2012, 28, 1764-1770.

12. Lüsse, S.; Arnold, K. The interaction of poly (ethylene glycol) with water studied by $1 \mathrm{H}$ and $2 \mathrm{H}$ NMR relaxation time measurements. Macromolecules 1996, 29, 4251-4257. [CrossRef]

13. Peng, C.; Liu, J.; Zhao, D.; Zhou, J. Adsorption of hydrophobin on different self-assembled monolayers: The role of the hydrophobic dipole and the electric dipole. Langmuir 2014, 30, 11401-11411. [CrossRef]

14. Liu, J.; Liao, C.; Zhou, J. Multiscale simulations of protein G B1 adsorbed on charged self-assembled monolayers. Langmuir 2013, 29, 11366-11374. [CrossRef]

15. Yu, G.; Liu, J.; Zhou, J. Mesoscopic coarse-grained simulations of lysozyme adsorption. J. Phys. Chem. B 2014, 118, 4451-4460. [CrossRef] [PubMed]

16. Zhao, D.; Peng, C.; Zhou, J. Lipase adsorption on different nanomaterials: A multi-scale simulation study. Phys. Chem. Chem. Phys. 2015, 17, 840-850. [CrossRef] [PubMed]

17. Caballero-Herrera, A.; Nordstrand, K.; Berndt, K.D.; Nilsson, L. Effect of urea on peptide conformation in water: Molecular dynamics and experimental characterization. Biophys. J. 2005, 89, 842-857. [CrossRef] [PubMed]

18. Yu, X.; Wang, Q.; Lin, Y.; Zhao, J.; Zhao, C.; Zheng, J. Structure, orientation, and surface interaction of Alzheimer amyloid- $\beta$ peptides on the graphite. Langmuir 2012, 28, 6595-6605. [CrossRef]

19. Schuler, L.D.; Daura, X.; Van Gunsteren, W.F. An improved GROMOS96 force field for aliphatic hydrocarbons in the condensed phase. J. Comput. Chem. 2001, 22, 1205-1218. [CrossRef]

20. Van Der Spoel, D.; Lindahl, E.; Hess, B.; Groenhof, G.; Mark, A.E.; Berendsen, H.C. GROMACS: Fast, flexible, and free. J. Comput. Chem. 2005, 26, 1701-1718. [CrossRef]

21. Hess, B.; Kutzner, C.; Van Der Spoel, D.; Lindahl, E. GROMACS 4: Algorithms for highly efficient, load-balanced, and scalable molecular simulation. J. Chem. Theory Comput. 2008, 4, 435-447. [CrossRef] [PubMed]

22. Berendsen, H.J.C.; Postma, J.P.M.; van Gunsteren, W.F.; Hermans, J. Interaction Models for Water in Relation to Protein Hydration; Pullman, B., Ed.; Springer: Dordrecht, The Netherlands, 1981; pp. 331-342.

23. Essmann, U.; Perera, L.; Berkowitz, M.L. A smooth particle mesh Ewald method. J. Chem. Phys. 1995, 103, 8577-8593. [CrossRef]

24. Berendsen, H.J.C.; Postma, J.P.M.; van Gunsteren, W.F.; DiNola, A.; Haak, J.R. Molecular dynamics with coupling to an external bath. J. Chem. Phys. 1984, 81, 3684-3690. [CrossRef]

25. Hess, B.; Bekker, H.; Berendsen, H.J.C.; Fraaije, J.E.M. LINCS: A linear constraint solver for molecular simulations. J. Comput. Chem. 1997, 18, 1463-1472. [CrossRef]

26. Dismer, F.; Hubbuch, J. A novel approach to characterize the binding orientation of lysozyme on ion-exchange resins. J. Chromatogr. A 2007, 1149, 312-320. [CrossRef]

27. Clifton, L.A.; Paracini, N.; Hughes, A.V.; Lakey, J.H.; Steinke, N.-J.; Cooper, J.K.; Gavutis, M.; Skoda, M.W.A. Self-Assembled fluid phase floating membranes with tunable water interlayers. Langmuir 2019, 35, 13735-13744. [CrossRef]

28. Shao, Q.; He, Y.; White, A.D.; Jiang, S.Y. Difference in hydration between carboxybetaine and sulfobetaine. J. Phys. Chem. B 2010, 114, 16625-16631. [CrossRef] [PubMed]

29. Liu, Y.L.; Zhang, D.; Ren, B.P.; Gong, X.; Liu, A.; Chang, Y.; He, Y.; Zheng, J. Computational investigation of antifouling property of polyacrylamide brushes. Langmuir 2020, 36, 2757-2766. [CrossRef] [PubMed]

30. Hayashi, T.; Tanaka, Y.; Koide, Y.; Tanaka, M.; Hara, M. Mechanism underlying bioinertness of self-assembled monolayers of oligo(ethyleneglycol)-terminated alkanethiols on gold: Protein adsorption, platelet adhesion, and surface forces. Phys. Chem. Chem. Phys. 2012, 14, 10196-10206. [CrossRef] [PubMed] 